\title{
Analysis on Construction of Teaching Quality Monitoring System of Adult Higher Education
}

\author{
Ji Xian \\ School of Adult Education \\ Jiangyin Polytechnic College \\ Jiangyin City, Jiangsu Province, 214431 China
}

\begin{abstract}
The teaching process indudes "teaching" and "learning" of two aspects, and the teaching process of adult higher education is the autonomous learning process of students under the guidance of teachers. It respectively establishes scientific and reasonable "teaching" quality monitoring system and "learning" quality monitoring system, to respectively conduct monitoring of the whole teaching process from "teaching" and "learning" of the two aspects, in order to effectively improve the teaching quality of adult higher education.
\end{abstract}

Keywords-adult education; higher education; teaching quality; monitoring system;

\section{Introduction}

For a long time, due to the lack of research, the adult higher education teaching quality monitoring of school teaching management department basically refers to higher education teaching quality monitoring system for its monitoring. But the education object, teaching form and students' learning ability and other main teaching links and elements of adult higher education have a great difference with ordinary higher education, which fully uses ordinary higher education quality monitoring system for monitoring, and it will easily cause weak pertinence and monitor mismatch. The key to improving adult higher education quality is to construct a set of systematic, complete and objective teaching quality monitoring system, which can meet the era requirement and adapt to the talent cultivation goal and requirement of adult higher education, highlighting application and practical talent cultivation quality feature and with operation.
The teaching process includes "teaching" and "learning" of two processes, and the two processes, on one hand, are mutually independent complete individuals; on the other hand, they make mutual penetration and influence. Among them, "teaching" is the basis, and good teachers can ensure that students learn well. "Learning" is the basis, and only students learn well that it can finally ensure the good teaching effect. In order to ensure the teaching quality of adult higher education, it must construct monitoring system for its monitoring from the "teaching" and "learning" of the two aspects.

\section{II. “Teaching” Quality Monitoring System}

The "teaching" process mainly includes teaching plan, teaching outline fabrication, teaching process implementation and teaching evaluation of three lin ks. In order to ensure the "teaching" quality, we should do the monitoring work for the three links.

\section{1) Fabricating Monitoring for Teaching Plan and}

\section{Teaching Outline}

The teaching plan monitoring should at least reflect in the following aspects.

(1)Monitoring of curricular system. The course setting should fully reflect the adult education feature according to professional cultivation goal. So for the course system monitoring, it can be conducted from four dimensions: First, whether the sum of all the courses can meet the minimum knowledge structure requirement of professional cultivation goal. Second, whether course setting can reflect the application and practicality adult education cultivation feature. Third, whether course 
setting can reflect era feature. The so-called era feature can reflect the latest scientific application achievement or professional prospect course. Fourth, whether the course systemhave necessary practical teaching link.

(2)Monitoring of course teaching time. Because adult education teaching is a learning form of taking teachers as the aided and students'self-learning as the main body. Thus, in teaching plan, it has the rules of each course learning time. Apart from determining the total learning time, it should also rule the face-to-face learning time, self-learning time. If it has experiment content, it should make clear experiment learning time.

(3)Monitoring of course teaching outline. Course teaching outline is the course teaching guidance document according to profes sional cultivation goal and teaching plan requirement, and it takes outline form to rule the course teaching goal, task, knowledge, skill range, depth and system structure, teaching progress and teaching method's basic requirements.

(4)Monitoring of teaching plan and teaching outline revise. A better teaching plan and teaching outline can only reflect the fabricating profession and course development level, in order to meet the talent cultivation demands.

\section{2)Teaching Process Monitoring}

The teaching process implementation is essentially the process of overall implementing teaching plan according to teaching outline to organize teaching, in order to ensure teaching quality, and we need to do the following aspects of monitoring.

(1)Conducting monitoring for teaching plan and teaching outline implementation situation. Once the teaching plan and teaching outline are fabricated, the course must strictly open according to the teaching plan, and also it should conduct strict monitoring for face-to-face teaching, self-learning and experiment of the three types of learning implementation situation, in order to ensure the implementation. Not implementing the learning time will finally influence the learning effect of the course. The teachers should strictly organize teaching according to course teaching outline, and in the regulated range of outline, it makes innovation, without random "lacking". On ly by ensuring the two teaching documents of $100 \%$ implementation, it can ensure the whole course and professional teaching quality.

(2)Monitoring for teachers. We should select qualified teachers with adult education teaching rules, which is the key to ensuring course teaching quality. For teachers' monitoring, it needs to make comprehensive evaluation of teacher qualification, educational background, major limit, position situation, student evaluation, peer evaluation, ethics, enterprise practice experience and whether having adult teaching experience.

(3)Classroom teaching monitoring. The classroom teaching of complete adult education includes lessons, taking lessons and counseling of three parts, and the three parts complement each other and it is indispensable, and we can do the monitoring work from three aspects from statics and dynamics. Static monitoring mainly makes monitoring for the normal implementation situation of teaching routine. Through checking teaching daily and lecture form to monitor the lesson link. Through examining the assignment and correcting situation, answering situation and teaching materials providing situation, it can monitor the students' counseling process.

(4)Testing link monitoring. The testing link monitoring is the special link of the whole teaching link. The test itself has no influence on teaching quality, but from long-term aspect, our evaluation for teaching quality(accurately for students' learning quality evaluation) is mainly the testing, so the test changes teaching. The examination link organization directly influences the teaching quality and especially the learning quality.

The test link mainly includes test system, test papers, test organizations and test evaluation and analysis of the several links. We can do the monitoring work from three processes of before the test, in the test and after the test. The monitoring before the test is mainly whether the test system is complete, the test is standardized, how is the 
test printing and secret work and whether the test arrangement is serious.

\section{3) Monitoring of Centralized Practice Link}

The centralized practice link is to change others' knowledge into students' knowledge of the important link. It is of great help for students' comprehensively using knowledge to find problem and solving problem ability improvement. The centralized practice lin k main ly includes graduation practice and practice homework of the two parts. The graduation practice of adult education students is basically completed by students, and they are scattered in different units and school lacks of effective monitoring means and methods in its practice process, students normally take practice reports with seals to cope with.

\section{III. “Learning" Quality Monitoring System}

\section{1)Student Source Quality Monitoring}

Adapting to actual situation is the first principle of teaching. In recent years, the national adult entrance examination has several points to cause great attention. First, college enrollment eliminates the checking of high school graduation certificate, making junior graduates can pass adult college entrance examination to participate in adult higher education learning. Second, undergraduate enrollment score line gradually reduces. For Jiangsu, 2013 adult college entrance examination score college is 110 scores(science)/120 scores, and undergraduate is 105 . For 450 scores, the admission threshold is low. Third, the enrollment scale of industry and enterprise gradually expands.

\section{2)Learning Process Monitoring}

Students are the main body of learning. In the whole teaching link, students' learning process is to have decisive role for final learning result, and it needs to make key monitoring for the link. Students' learning process includes face-to-face process, self-learning process and practice lin $\mathrm{k}$ completion process and testing process. The face-to-face teaching process includes students' attendance and class and experiment completion situation. The self-learning process includes teaching material learning situation, homework completion situation, teachers' provided resource learning situation, teachers and students' interaction exchange situation. The practice link completion process includes graduation practice and graduation homework completion situation. The testing process main ly refers to students'taking part in tests.

\section{3)Learning Result Monitoring}

Students' learning quality is reflected through learning result. Students' learning result can be reflected through course learning performance. Thus, as the teaching management staff, they should pay attention to students' course learning performance, and according to students' performance change, they can make timely learning process intervention work of students, in order to ensure the learning process quality.

\section{4)Graduate Information Monitoring}

After graduates leave school, their evaluation for school cultivation quality and unit evaluation for graduates are important indexes of measuring a school talent cultivation quality. The school should pay great attention to the information, establishing tracking system of graduate information for regular tracking, feedback and evaluation, and the teaching management department should make the monitoring for this.

\section{Teaching Quality Monitoring Information Processing and Feedback}

In the whole teaching process, teaching monitoring is organized for implementation by teaching supervision department, and the teaching organization is organized for implementation by teaching department. The information exchange between the two departments will have delay, loss or distortion. Thus, in practice process, it should focus on monitoring information feedback timeliness, true and completeness. If it cannot get timely 
feedback of the monitoring result, the reflected problems cannot get timely solved, the monitoring work is virtual, which cannot have the role of any quality control. Also, the teaching department should make timely analysis and processing for the feedback information, and the processing result can feedback to supervision department for timely feedback, and the supervision department can conduct tracking for the result. Objective and scientific determining adult higher education teaching quality monitoring standard can improve teaching quality from "teaching" and "learning" of the two aspects, and we should insist in two aspects.

\section{References}

[1] Ji Xian. Study on adult higher education teaching quality evaluation index system[J.Continuous Education Research, 2013, (9) : 53-55.

[2] Qiang Ping. Practice and reflection of improving adult education teaching quality[J].Chinese University Teaching, 2014, (1): 78-80.

[3] Fan Chao, Fan Min. Study on higher education teaching quality feedback mechanism[J].Education and Occupation. 2014, (5) : 26-28. 